\title{
Value Pluralism and the \\ Two Concepts of Rights
}

\author{
HORACIO SPECTOR*
}

TABLE OF CONTENTS

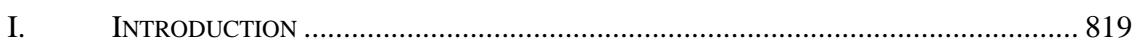

II. THE WILL THEORY AND THE INTEREST THEORY OF RIGHTS................................. 824

III. VALUE INCOMMENSURABILITY AND DISCOURSE INCOMMENSURABILITY:

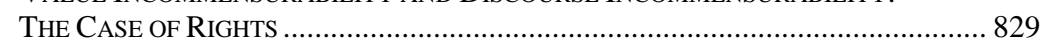

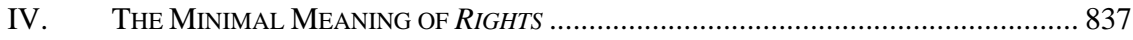

\section{INTRODUCTION}

Philosophers and legal theorists still disagree about the correct analysis of rights, both moral and legal. The "Will Theory" and the "Interest Theory" - the two main views - can each account for various features of rights, but neither of them is totally satisfactory. The controversy has now been running for decades and seems irresolvable. ${ }^{1}$ I will contend in this paper that the discussion of "value pluralism" in the Berlinian tradition can illuminate the debate over the concept of rights.

* I am grateful to Larry Alexander, Dick Arneson, Daniel Weinstock, and especially my commentator, Professor Christopher Wonnell, for their helpful comments during the Conference on Isaiah Berlin, Value Pluralism, and the Law held at the University of San Diego School of Law on February 20-21, 2009. I have also benefited from comments made by Marcelo Ferrante, Jeff McMahan, Guido Pincione, Dave Schmidtz, and Fernando Tesón.

1. For a state of the question, see Matthew H. Kramer et AL., A Debate over Rights: PHILOSOPHICAL ENQUIRIES 1-2 (1998). 
Value pluralism says that there is a plurality of conflicting and incommensurable universal values. ${ }^{2}$ Values are said to be incommensurable "when they raise radically distinct considerations such that there seems, prima facie, to be no reason to rank one ahead of another in all or most cases." ${ }^{3}$ This is the conception of incommensurability that Isaiah Berlin embraced. Because it does not include a time variable, I call it "synchronic value pluralism.” It centrally claims that there is no general procedure to rank abstract values in such a way so as to allow the resolution of practical conflicts in particular cases. There is a second conception of value pluralism that I call "diachronic value pluralism." This conception maintains the theses of rivalry and incommensurability of values but incorporates time as a relevant variable. It claims that at any given time $(t)$ in the course of human history there is a plurality of conflicting and incommensurable universal values whose existence started at some time earlier than $t(t-1)$, and that it is possible for the plurality of values existing at $t$ to be a proper subset of a plurality of values that will exist at some time later than $t(t+1)$. This conception is committed to the view that new values emerge over time according to various cultural, political, and economic transformations. This does not mean that values are subjective or relative to a given culture. Rather, values emerge at a certain time, but their existence is objective and universal.

The diachronic conception of value pluralism draws on Joseph Raz's theory of values. Raz stresses the dependence of values on sustaining social practices. ${ }^{4}$ In fact, Raz argues that although the existence of values has social preconditions, as long as the preconditions are met and the corresponding values come into being, their existence persists without restrictions. ${ }^{5}$ Raz explains the asymmetry of emergence and continued existence in this way:

The usual pattern is for the emergence, out of previous social forms, of a new set of practices, bringing into life a new form: monogamous marriage between partners chosen by each other, the opera, and so on, with their attendant excellences. Once they come into being, they remain in existence even if the sustaining practices die out. ${ }^{6}$

Now, Raz does not say that his "social dependence" thesis implies value pluralism. Rather, he says that the thesis that values depend on social practices can accommodate value pluralism because it implies that value

\footnotetext{
2. George Crowder, Liberalism And Value PluRalism 45 (2002).

3. Id. at 53 .

4. Joseph Raz, The Practice of Value 21-22 (R. Jay Wallace ed., 2003).

5. Id.

6. Id.
} 
judgments depend on genres or kinds that evolve culturally, for example, opera, sports, and democratic politics, and different genre-bound evaluations need not be logically contradictory. ${ }^{7}$ Therefore, Raz's social dependence thesis is not the same as diachronic value pluralism, but there is a resemblance between the two positions.

Political and legal culture has been diversified by the cumulative accretion of values that express human beings' concerns in reaction to different historical predicaments. New value paradigms coexist with older value paradigms because the latter are central to forms of life that continue to define people's senses of identity and meaningfulness. By the same token, values are incommensurable with one another because each value presupposes a distinct form of life that cannot be ranked along an ordering of forms of life. ${ }^{8}$ That is, values are incommensurable with each other due to the incommensurability of their supporting forms of life. An outsider can interpret the value paradigm of an alien society even if he does not share the relevant form of life, provided he adopts a participant's point of view. In adopting the internal perspective, the outsider translates the beliefs and concerns of the foreign society into his own forms of life and value paradigms. Other things being equal, the greater the distance between the outsider's paradigms and those of the society he wants to understand, the higher the risk that the translation will only be an approximate one. ${ }^{9}$

I will argue that the diachronic conception of value pluralism explains why conceptual fragmentation in normative language is a natural and pervasive phenomenon. Indeed, the meaning of normative terms embedded in successive incommensurable value paradigms often varies so radically that the concepts denoted by those terms disintegrate into different concepts. Specifically, I will claim that a radical change of value paradigm has fragmented the concept of rights, and that value incommensurability stands in the way of the concept's coalescing back. The thesis of conceptual fragmentation of normative language explains in turn why the perennial debate on the analysis of rights has not yet been brought to a close. In fact, rival and incommensurable value

7. Id. at $44-45$.

8. BeRnard Williams, Ethics AND the Limits of Philosophy 157-58 (1985). Bernard Williams also says that different cultures or forms of life may be incommensurable with each other, but he does not mention values or value pluralism. Id.

9. See H.L.A. HART, THE CONCEPT OF LAW 55 (1961). 
paradigms lie behind the Will Theory and the Interest Theory. ${ }^{10}$ Because legal systems reflect a diachronic plurality of rival and incommensurable values, the term right is subject to radical semantic variation. Therefore, any analysis of the concept of rights that goes beyond their mere correlativity to duties or their relation to state enforcement will likely fail to explain existing linguistic practices.

The idea to be explored in this paper is kindred to two preceding views, one in the philosophy of science and the other in moral philosophy. The first is Paul Feyerabend's thesis on the radical variance of the meaning of terms embedded in successive scientific theories. ${ }^{11}$ Feyerabend claims that the primitive terms of a theory ( $T^{\prime}$ ) often cannot be defined by reference to the primitive descriptive terms of a different theory $(T)$, nor correlated to them via correct empirical generalizations. ${ }^{12}$ For instance, "impetus" in Aristotle's theory of motion cannot be defined within the vocabulary of Newton's mechanics. In fact, within Aristotelian mechanics, "[t]he impetus of a body in empty space which is not under the influence of any outer force remains constant." ${ }^{13}$ Under Newton's mechanics, this proposition is empirically adequate, but there is no entity that acts as the cause of motion. Momentum, the most obvious candidate, is rather the result of motion. Even if we formed the concept of such a force, Newton's second law would imply a zero value for such a force in the case of inertial motion. ${ }^{14}$

The second view is Alasdair MacIntyre's thesis on conceptual fragmentation in normative discourses. MacIntyre argues that the

10. I develop here an idea originally proposed in Horacio Spector, Is the Will Theory of Rights Superseded by the Hybrid Theory?, in 2 SOCIAL, POLITICAL, \& LEGAL Philosophy: Law: Metaphysics, Meaning, and Objectivity 289, 294 (Enrique Villanueva ed., 2007). Chris Wellman and Siegfried Van Duffel also claim that the dispute over the concept of rights relies on competing values and rival paradigms: Christopher Heath Wellman, Feinberg's Two Concepts of Rights, 11 LEGAL THEORY 213 (2005); Siegfried Van Duffel, The Nature of Rights (July 9, 2008) (unpublished manuscript), available at http://ssrn.com/abstract $=1157282$. However, Wellman's and Van Duffel's arguments are very different from the one developed here. For instance, neither Wellman nor Van Duffel discusses the relationship between value pluralism and the two concepts of rights.

11. PAUl K. Feyerabend, Explanation, Reduction and Empiricism, in 1 Philosophical Papers: Realism, Rationalism, and SCIENTIFIC MethoD 44 (1981). See also Paul K. Feyerabend, On the "Meaning" of Scientific Terms, 62 J. PHIL. 266 (1965). This thesis overlaps with Kuhn's famous thesis on the incommensurability of scientific theories, although Kuhnean incommensurability far exceeds the strictly semantic conception that I focus on in the text. See, e.g., Thomas S. Kunn, The ROAD SinCE STRUCTURE 33-57 (James Conant \& John Haugeland eds., 2000).

12. FEYERABEND, supra note 11, at 74-91.

13. Id. at 64 .

14. Id. at 57-61. Newton's second law of motion says that "[t]he acceleration of a body of mass $m$ is related to the force acting on it by $F=m a$." N.M.J. WoODHOUSE, SPECIAL RELATIVITY 5 (2003). 
Enlightenment project of trying to find a rational basis for moral beliefs is foredoomed to failure because it relies on an ineradicably discrepant set of moral beliefs and a deeply different vision of human nature. ${ }^{15}$ MacIntyre says that the modern philosophers "inherited incoherent fragments of a once coherent scheme of thought and action and, since they did not recognize their own peculiar historical and cultural situation, they could not recognize the impossible and quixotic character of their self-appointed task." ${ }^{16}$ For instance, he shows that the meaning of ought was fixed in the classical Aristotelian framework in a way that Enlightenment radically changed. ${ }^{17}$ Within the former framework says MacIntyre:

\begin{abstract}
To say what someone ought to do is at one and the same time to say what course of action will in these circumstances as a matter of fact lead toward a man's true end and to say what the law, ordained by God and comprehended by reason, enjoins. Moral sentences are thus used within this framework to make claims which are true or false. ${ }^{18}$
\end{abstract}

My plan is as follows. In Part II, I will indicate how the Will Theory and the Interest Theory each capture distinct features of the usage of right in contemporary moral and legal discourse. However, I will also argue that neither of the two theories is successful in explaining all the properties of rights. In Part III, I will argue that the debate between the two theories is irresolvable because the Will Theory and the Interest Theory reflect the meaning of rights within rival and incommensurable value paradigms existing in today's moral and legal culture. The incommensurability of the underlying value paradigms leads to radical variance in the meaning of the term rights, despite the obvious homonymy. Specifically, I will argue that the Will Theory represents a fragment of a once integrated normative framework, and that it is in abstraction from such framework that this theory becomes beset by puzzles. In turn, the Interest Theory is incompatible with the properties attributed to rights in the older value paradigm. All in all, radical meaning variance makes a neutral external analysis of rights impossible. Therefore, there is no reason to try to choose between two theories that mistakenly assume meaning invariance of normative terms across rival

15. Alasdair MacIntyre, After Virtue: A Study in Moral Theory 51-61 (2d ed. 1984).
16. Id. at 55.
17. Id. at 53 .
18. Id. 
and incommensurable value paradigms.

Finally, in Part IV, I will claim that the term right nonetheless has an invariant conceptual core across the two main value paradigms in which it is embedded. Basically, rights entail state enforceability. This minimal semantic overlap among various usages of rights explains the confusing coexistence of various value paradigms and their associated normative terms.

\section{THE WILL THEORY AND THE INTEREST THEORY OF RIGHTS}

The Will Theory was introduced in Anglo-American legal theory by H.L.A. Hart under the name of "Choice Theory," but it was classically defended by a number of German jurists in the nineteenth century, and its roots go back to Kant. ${ }^{19}$ Hart endorses the Will Theory because it can explain why rights reflect a distinctive concern for the individual. Under this view, a right expresses the idea of "one individual being given by the law exclusive control, more or less extensive, over another person's duty so that in the area of conduct covered by that duty the individual who has the right is a small-scale sovereign to whom the duty is owed." ${ }^{20}$ Hart goes on to say that a right holder has at his disposal the "fullest measure of control" when he possesses: the power to waive or extinguish the duty, the power to enforce it by legal actions after actual or threatened breach of the duty, and the power to waive or extinguish the obligation to pay compensation for violation of the duty. ${ }^{21}$ So, for the Will Theory, Hohfeldian powers are central to rights. ${ }^{22}$

In its early formulation as the "Benefit Theory," the Interest Theory was first suggested by Bentham. ${ }^{23}$ Under this view, A's having a right to $X$ against $B$ means that $A$ is the beneficiary of $B$ 's duty to do $X$. The German legal scholar Rudolf von Jhering proposed a clearly recognizable form of the Interest Theory when he changed his jurisprudential position from legal formalism to legal instrumentalism. ${ }^{24}$ Von Jhering famously defined a legal right as a "legally protected

19. N.E. Simmonds, Rights at the Cutting Edge, in A DEBATE OVER Rights: PHILOSOPHICAL ENQUIRIES supra note 1, at 113, 135, 179.

20. H.L.A. HART, Legal Rights, in ESSAYS ON BENTHAM: STUDIES IN JURISPRUDENCE AND POLITICAL THEORY 162, 183 (1982).

21. Id. at 183-84 (footnote omitted).

22. For Hohfeld, a normative power is a situation in which person $A$ can claim or waive another person $B$ 's duty. More generally, a normative power is a situation in which a person can modify the normative position of another by his will.

23. See JeREMy Bentham, The PRinciples OF MORALS AND LEGISLATION 223-26 (Prometheus Books 1988) (1789); JEREMy BENTHAM, Of LAWS IN GENERAL 57 (H.L.A. Hart ed., 1970).

24. See Jürgen Habermas, Between Facts and Norms: Contributions to a DisCOURSE THEORY OF LAW AND DEMOCRACY 86 (William Rehg trans., 1996). 
interest." 25 In its most plausible version, proposed by Joseph Raz, the Interest Theory holds that $A$ 's having a right to $X$ against $B$ means that an interest of $A$ 's, or an aspect of his well-being, is a sufficient reason for holding $B$ under a duty. ${ }^{26}$

Both the Will Theory and the Interest Theory provide partial explanations of some essential features of rights in contemporary normative discourse, but none of them can explain the whole set of essential features. Such features are that some rights are alienable but others are necessarily inalienable; paternalistic interferences with the right holder-within the range of his rights-are impermissible; all rights, regardless of their grounding value, outweigh or trump other normative considerations grounded in subjective interests; and some rights are more important than others.

If rights are understood as normative positions that satisfy all of these features, there are no rights according to the Will Theory and the Interest Theory. A noninstantiated concept of rights is not helpful because one essential condition of any analysis of rights is that there are some rights, for example, the right to liberty or privacy. Although both theories fail, the reason for each theory's failure is different. The Will Theory fails because it gives us only a fragment of a once unified and coherent value framework. The Interest Theory fails because it subordinates rights to the contingencies of varying subjective interests. This malleable notion does not fit at all within a previous value paradigm that still governs our linguistic practices.

Let us discuss these failures in turn. ${ }^{27}$ First, the Will Theory cannot account for inalienable rights, that is, for rights that the right holder cannot waive or relinquish. The problem is that inalienable rights are considered fundamental in modern liberal culture. It seems paradoxical that the most fundamental rights, like the rights to life or liberty, are

25. RUDOLF VON JHERING, GEIST DES RÖMISCHEN RECHTS AUF DEN VERSCHIEDENEN STUFEN SEINER ENTWICKLUNG 339 (Leipzig, Breitkopf \& Härtel 1865) (author's translation).

26. Joseph Raz, The Nature of Rights, in The Morality of FreEDOM 165, 166 (1986). The Interest Theory has also been defended by NEIL MACCORMICK, Children's Rights: A Test-Case for Theories of Right, in Legal Right and Social Democracy: EsSAYs IN LEgAl AND POLITICAL PHILOSOPHY 154, 163 (1982), and D.N. MacCormick, Rights in Legislation, in LAW, MORALITY AND SOCIETY: EsSAYS IN HONOUR OF H.L.A. HART 189, 192 (P.M.S. Hacker \& J. Raz eds., 1977).

27. There are other failures that I will not discuss in this paper. For instance, the Interest Theory fails to explain why there are rights that are not in the right holder's interest, such as the right to an inherited troublesome property. See George W. Rainbolt, Rights Theory, 1 PHIL. CoMPASs 11, 14 (2006). 
precisely those rights for which the crucial element identified by the Will Theory, namely, the control over the correlative duty, is substantially absent. ${ }^{28}$ According to the Will Theory, inalienable rights cannot be full-fledged rights.

A related problem is that the Will Theory is incapable of accounting for rights in criminal law contexts. Hart says that in the criminal law rights have the lesser measure of control. ${ }^{29}$ But this is not a serious problem. In effect, right holders do have a considerable measure of control under the criminal law, too, because they can usually waive the private law obligations whose breach is a prerequisite to considering certain conduct as a criminal offense. For instance, if Amy waives her ownership right over her piano and no one else claims it, Matt's taking control of the piano cannot count as theft. Clearly, the right holder lacks this type of control with respect to murder, for example. In many cases of this kind, powers are wanting because the relevant right is an inalienable one, so the preceding difficulty applies. What the right holder cannot typically do under the criminal law is to cancel the offender's criminal liability because prosecution is in most cases a public matter. This would create a problem for the Will Theory if it were plausible to hold that victims have a right to determine the punishment of perpetrators. The Interest Theory cannot explain inalienability either. Indeed, if rights are grounded on subjective interests, why could a right holder not relinquish his right if he were to pursue his interests more effectively in this way? According to the Interest Theory, alienation or nonalienation are matters to be assessed on the basis of the promotion of subjective interests, and therefore, on a case-by-case basis, rather than as a matter of principle.

Second, the Interest Theory cannot explain why moral rights generally block interferences intended to advance more successfully the rights holder's interests. ${ }^{30}$ According to the nonconsequentialist view of moral rights, if $A$ has a moral right to $X$, this right is valid whatever the consequences of its fulfillment or infringement. This abstract idea entails that $A$ 's moral right to $X$-although not relinquished-holds even if $A$ does not have a subjective interest in $X$, and even if $A$ does have an interest in non- $X$. The latter clause rules out paternalistic interferences. Because the only basis for holding $B$ under the duty to respect $A$ 's right is an interest of $A$ 's, $B$ could justifiably infringe $A$ 's right when doing so

28. MacCormick, supra note 26, at 196.

29. HART, supra note 20, at 184.

30. Eric Mack, In Defense of the Jurisdiction Theory of Rights, 4 J. ETHICs 71, 84 (2000), reprinted in RIGHTS, EQUALITY, AND LIBERTY 71 (Guido Pincione \& Horacio Spector eds., 2000). 
can advance more effectively A's interests. For instance, if the right to reject medical treatment were based on the interests of the patient, it might be possible to justify the imposition of a blood transfusion on a Jehovah's Witness. This difficulty also bears on the Will Theory because the fact that right holders have powers over correlated duties is consistent with allowing the government to cancel those powers when the government can better promote in this way the interests of the right holder. Because the Will Theory fails to display the grounds of the relevant powers, it cannot forbid paternalism on a principled basis.

The third problem, noted by Joseph Raz with respect to the Interest Theory, is that it fails to explain why the stringency of some rights does not match the importance of the right holder's interests. Raz writes that, more often than not, we attach greater importance to a right than to its alleged underlying interests. ${ }^{31}$ Because Raz conceives of rights as just morally protected interests, he must look elsewhere for the explanation of the differential importance of some rights. So he appeals to the value of those rights for the common good, particularly for the sustenance of a liberal culture. $^{32}$ Similarly, the Will Theory lacks the ability to explain the relative importance of various rights. Like the Interest Theory, it must avail itself of further claims to justify why the right to life, for instance, is more important than the right to play dangerous games, such as Russian roulette.

The fourth and most fundamental problem for both the Will Theory and the Interest Theory lies elsewhere. Eric Mack identified this problem with respect to the Interest Theory. This theory cannot account for the essential connection between moral rights and individuals' inviolability. ${ }^{33}$ Contemporary nonconsequentialist moral philosophers emphasize this connection in discussing the concept of moral rights. ${ }^{34}$ Thus, Robert Nozick has famously argued that rights are "side

31. Joseph Raz, Ethics in the Public Domain: Essays in the Morality of LAW AND POLITICS 30-32 (1994).

32. Id. at 33-34.

33. Eric Mack has argued that the prohibition of trade-offs and the principled rejection of paternalism are two essential features of rights. See Mack, supra note 30, at 95-96.

34. Ronald Dworkin, TAKing Rights Seriously 240 (1978); 2 F.M. KAMM, Morality, Mortality: Rights, Duties, and Status 259-89 (1996); Horacio SPECTOR, AutONOMY AND Rights 163-78 (1992); Judith JARVIS ThOMSON, THE REALM OF Rights 123-48 (1990); Alan Gewirth, Are There Any Absolute Rights?, in THEORIES OF Rights 91 (Jeremy Waldron ed., 1984); Amartya Sen, Rights and Agency, 11 PHIL. \& Pub. AfF. 3, 5 (1981). 
constraints," that is, deontic constraints. ${ }^{35}$ On this view, rights are correlative to moral prohibitions in the form of: "Do not violate constraints $C$." Thus, rights forbid treating people in certain ways, and they must be respected no matter the overall benefits that could be obtained by alternative conduct. That is, in principle, rights may not be infringed even when this can lead us to greater utility overall, and more strikingly, even when by infringing them we can minimize the overall violation of rights. ${ }^{36}$ Therefore, $A$ 's right is also independent from other people's subjective interests, that is, projects, preferences, and decisions. This also includes cases in which ignoring or violating $A$ 's right is needed to produce a greater nonmoral or moral good. Banning such "maximizing" violations reflects the Kantian ideal that autonomous individuals are inviolable. ${ }^{37}$ However, nonconsequentialists disagree about the degree of inviolability to which persons are entitled. Some consequentialists deny that rights are absolute and say that it is permissible to infringe a right if infringing it is sufficiently better for third parties than not infringing it is for the right holder. ${ }^{38}$

The Interest Theory cannot explain why moral rights are side constraints because it regards the value of rights as based on the right holder's subjective interest. Because this interest can conflict with other people's interests, the Interest Theory tends to accept the sacrifice of rights for the sake of overall interest maximization. Mack's argument is really more complex. He notes that interests can have either agentneutral or agent-relative value. ${ }^{39}$ A's interest has agent-neutral value when it is valuable to everyone, that is, when $A$ 's interest provides reasons to every agent, including $A$. By contrast, $A$ 's interest has agentrelative value when it provides reasons only to $A$, who is the bearer of the interest. In the former case, rights fall prey to the utilitarian calculus. Because the normative force of rights is grounded on the right holder's interests, there is always the possibility that those interests will be outweighed by other people's interests. Alternatively, if the right holder's interests have only agent-relative value, the theory fails to explain how those interests can justify holding someone else under a duty. ${ }^{40}$

35. Robert Nozick, ANARChy, State, AND Utopia 29 (1974). "Deontic constraint" is a term of art in moral philosophy that denotes a moral duty or prohibition that a moral agent ought to respect regardless of the consequences. Not all deontic constraints are rights because some moral duties need not be correlated to rights.

36. Id. at 29-33. See also SPECTOR, supra note 34, at 163-78.

37. NozICK, supra note 35, at 35.

38. See ThOMSON, supra note 34 , at 151 .

39. Mack, supra note 30, at 78-79.

40. Id. at 83-84. 
The Will Theory is affected by another version of the same problem. This theory focuses on the powers of right holders but ignores the underlying autonomy-based justification. Hart, for example, suggests that the justification of those powers associated with the Will Theory is an interest in autonomous choice. ${ }^{41}$ Under the Kantian view, however, rights cannot be grounded on interest-not even an interest in autonomous choice-because that would disregard the value of autonomy. There is nothing morally special about powers that prevent us from ignoring them, that is, breaching the controlled duties, if that is needed to produce greater good or to minimize the violations of rights. Although the Interest Theory includes an inadequate form of justification, the Will Theory entirely lacks justification. In either case, however, the result is much the same: an inability to capture the anticonsequentialist features of rights in today's moral language. ${ }^{42}$

\section{VALUE INCOMMENSURABILITY AND DISCOURSE INCOMMENSURABILITY: THE CASE OF RIGHTS}

Moral and legal rights were deep-seated in the value paradigm of individual autonomy $\left(V_{1}\right)$ prevailing from the seventeenth to the nineteenth centuries. The epitome of this paradigm value is Kant's theory of rights. Under his doctrine, legal rights are public and institutional ways of recognizing the status of persons as autonomous beings. ${ }^{43}$ Because rights are based on the status of individuals as autonomous agents, they are part and parcel of a fundamentally deontological, nonconsequentialist moral outlook. Legal rights respect individual autonomy by vesting in individuals the powers that the Will Theory picks out. It is no surprise that the Will Theory focuses on rights in property and contract law, which are the cornerstone of Kant's conception of law. ${ }^{44}$ The Will Theory captures only a fragment of the meaning of rights in the value paradigm of individual autonomy.

41. HART, supra note 20, at 188-89.

42. Gopal Sreenivasan has offered an ingenious "hybrid theory" that tries to avoid the difficulties. See Gopal Sreenivasan, A Hybrid Theory of Claim-Rights, 25 OxFORD J. Legal Stud. 257 (2005), reprinted in 2 Social, Political, \& LEGAL PHILOSOPHY: LAW: METAPHYSICS, MEANING, AND OBJECTIVITY, supra note 10, at 263. I have criticized this theory in Spector, supra note 10.

43. Arthur Ripstein, Kant on Law and Justice, in The Blackwell Guide tO KANT's ETHICS 161 (Thomas E. Hill, Jr. ed., 2009).

44. See Jürgen Habermas, Paradigms of Law, 17 CARDOZO L. REV. 771, 772 (1996). 
Therefore, the Will Theory is an incomplete account of a more substantial value paradigm, that is, the paradigm of individual autonomy, which once dominated the normative discourse. Within this paradigm, rights are "trumps" grounded in personal autonomy and capable of overriding a good deal of consequentialist considerations. If the Will Theory were restored in such a way so as to mention both powers and to display their autonomy-based justification, it could easily explain why moral rights act as deontic constraints. Moreover, it could explain why some rights are inalienable, that is, because they are indispensable for preserving man's autonomous rational nature; why paternalistic interferences with right holders are generally unacceptable, that is, because they disregard rational autonomous agency; and why some rights are more important than others regardless of the strength of their underlying subjective interests, that is, because those more important rights are prerequisites for the existence and action of rational human agency.

The exemplar I use for the value paradigm of individual autonomy is Kant's Doctrine of Right, the first part of The Metaphysics of Morals, in which he examines at length the idea of moral rights as elements of a theory of justice. ${ }^{45}$ Kant poses a fascinating question: "But why is the doctrine of morals usually called (especially by Cicero) a doctrine of duties and not also a doctrine of rights, even though rights have reference to duties?"46 He goes on to answer:

The reason is that we know our own freedom (from which all moral laws, and so all rights as well as duties proceed) only through the moral imperative, which is a proposition commanding duty, from which the capacity for putting others under obligation, that is, the concept of a right, can afterwards be explicated. ${ }^{47}$

Kant thinks that although duties have an epistemic priority over rights, rights are fundamental in the justification of law as a system of external sanctions. In Kant's words, "Right is therefore the sum of the conditions under which the choice of one can be united with the choice of another in accordance with a universal law of freedom." 48 This principle seems to be an application of Kant's "Categorical Imperative" to the specific problem of distributing the freedom of autonomous beings through a system of universal coercive norms. ${ }^{49}$ In a sense, both duties and rights

45. Immanuel Kant, The Metaphysics of Morals 31-32 (Mary Gregor ed. \& trans., Cambridge Univ. Press 1996).

46. Id. at 31 .

47. Id. at 31-32 (emphasis and footnotes omitted).

48. Id. at 24 .

49. The Categorical Imperative is the fundamental unconditioned principle of Kant's moral theory. In its first, best known formula, the Categorical Imperative says: "[A]ct only in accordance with that maxim through which you can at the same time will that it become a 
have a subordinate role in Kant. It is one fundamental duty-enshrined by the Categorical Imperative- that grounds the whole system of duties and rights. Practical reason, a necessary aspect of the noumenal self, imposes this duty on the moral agent and, in so doing, secures his freedom-both negative freedom from external causation and positive freedom or self-determination. At that very abstract level, moral duty and metaphysical freedom come together and indeed constitute two inextricable sides to the same thing. Hegel expresses this view in a forceful way: "In duty, the individual liberates himself so as to attain substantial freedom." 50

In the second half of the nineteenth century, the paradigm of individual autonomy and its associated picture of rights protecting the liberty spheres of autonomous and inviolable individuals started to give way to a different paradigm centered on subjective interests, especially those appertaining to politically influential groups. ${ }^{51}$ Rights ceased to be exclusively regarded as a way of recognizing the status of autonomous agents and also became normative devices for enhancing the interests of some groups-unionized workers, consumers, and so on-or for implementing social goals such as solidarity and welfare. Yet, the old paradigm did not vanish. Rather, both paradigms started to clash in legal and moral thought.

The value paradigm of subjective interests $\left(V_{2}\right)$ represented a fundamental change with respect to the value paradigm of individual autonomy. Instead of viewing law as an institution to demarcate and protect spheres of nonintervention, the new paradigm regards law as an instrument for seeking collective goals. We might speculate that the new paradigm was facilitated by the emergence of an industrial economy and a concomitant urban society in which a frictionless, physical demarcation of ownership rights was no longer a recipe for coping with the violent and intractable conflicts that those new forms of life had aroused. Because the range of collective goals to be sought under the new paradigm is vast and varies with the political equilibriums of the

universal law.” ImMANUEL KANT, GROUNDWORK OF THE METAPHYSiCS OF MORALS 31 (Mary Gregor ed. \& trans., Cambridge Univ. Press 1998) (emphasis omitted).

50. G.W.F. Hegel, ElEments of The Philosophy of Right 192 (Allen W. Wood ed., H.B. Nisbet trans., Cambridge Univ. Press 1991).

51. Habermas, supra note 44, at 771-72. See also MARY ANN GLENDON, RighTS TAlK: The IMPOVERISHMENT OF Political Discourse 18-46 (1991); Duncan Kennedy, Form and Substance in Private Law Adjudication, 89 HARV. L. REV. 1685, 1728-30 (1976). 
day, it is congenial with the working of democratic decisionmaking institutions envisaged as "machines" that produce collective interests worthy of support and, therefore, various generations of rights that claim for political recognition and enforcement.

The difference in value paradigms explains the radical semantic variation of the term right as deployed in the paradigm of individual autonomy and the paradigm of subjective interests. That is, because the values shaping each paradigm are rival and incommensurable with each other, the meaning of rights in $V_{1}$ (rights ${ }_{1}$ ) and that of rights in $V_{2}$ $\left(\right.$ rights $_{2}$ ) are radically distinct. The point is that rights and rights $_{2}$ are radically different concepts because they are embedded in rival and incommensurable value paradigms. Today's normative language includes both terms but in ambiguous fashion.

Role/inferential semantics provide the most fruitful framework to discuss the radical variation of rights in connection with diachronic value pluralism. ${ }^{52}$ Under my favored interpretation of the semantics of moral terms, the meaning of a term $(t)$ is not given by a network of platitudinous propositions in which $t$ is a node. Rather, $t$ 's meaning is given by a set of basic rules that govern deductive inferences from or to propositions that centrally contain $t$. Accordingly, the meaning of rights in the paradigm of individual autonomy, that is, rights ${ }_{1}$, might be given, for instance, by the following basic inference rules:

52. The literature on role/inferential semantics of moral or legal terms includes: Alf Ross, Tû-Tû, 70 Harv. L. REV. 812, 817-18, 822 (1957); Aleksander Peczenik \& Horacio Spector, A Theory of Moral Ought-Sentences, 73 ARCHIV FÜR RECHTS- UND SOZIALPHILOSOPHIE 441, 441-42 (1987); Frank Jackson \& Philip Pettit, Moral Functionalism and Moral Motivation, 45 PHIL. Q. 20, 22-24 (1995); Ralph Wedgwood, Conceptual Role Semantics for Moral Terms, 110 PHIL. REV. 1, 12-13 (2001); Giovanni Sartor, Legal Concepts: An Inferential Approach 7 (Eur. Univ. Inst., LAW Working Paper No. 2008/03, 2008), available at http://papers.ssrn.com/sol3/papers.cfm?abstract_ id $=1093627$. 
(1) Acceptance of " $B$ 's doing $X$ with respect to $A$ disrespects $A$ 's autonomous rational agency” commits one to accepting " $A$ has a right against $B$ that $B$ does not do $X$."

(2) Acceptance of " $A$ has a right against $B$ that $B$ does not do $X$ " commits one to accepting " $B$ has a duty to $A$ not to do $X$."

(3) Acceptance of "right $R$ is essential to maintain $A$ 's autonomous rational agency" commits one to accepting “A cannot relinquish right $R$," that is, $R$ is inalienable.

By contrast, the meaning of rights in the paradigm of subjective interests, that is, rights $s_{2}$, might be conveyed, for instance, through the following rules:

(1*) Acceptance of " $B$ 's doing $X$ with respect to $A$ frustrates a relevant subjective interest of $A$ 's" commits one to accepting " $A$ has a right against $B$ that $B$ does not do $X$."

(2) Acceptance of " $A$ has a right against $B$ that $B$ does not do $X$ " commits one to accepting " $B$ has a duty to $A$ not to do $X$."

(3*) Acceptance of "the subjective interest grounding right $R$ is more important than the subjective interest grounding right $R$ ” commits one to accepting "other things being equal, $R$ is more important than $R$.”

This semantic approach makes it clear why the radical difference in the values that infuse the paradigm of individual autonomy and the paradigm of subjective interests change the semantic networks that provide the meaning of rights in such a way that rights ${ }_{1}$ and rights ${ }_{2}$ are irreducibly distinct. In fact, the set of rules (1), (2), and (3), which govern the meaning of rights $s_{1}$, and the set of rules $\left(1^{*}\right),(2)$, and $\left(3^{*}\right)$, which govern the meaning of rights ${ }_{2}$, cannot be coalesced into a coherent set containing the five rules (rule (2) is one and the same in both sets). In effect, rule (3) cannot be applied to rights 2 because, under the paradigm of subjective interests, it should be left to the right holder to establish whether relinquishing a right of his furthers more effectively his subjective interests. In turn, rule $\left(3^{*}\right)$ is inapplicable to rights ${ }_{1}$ 
because, under the paradigm of individual autonomy, the importance of rights cannot be grounded on the strength of the underlying subjective interests. Additionally, rules (1) and (1*) cannot be blended in an overarching network of semantic rules because autonomous rational agency and the satisfaction of subjective interests are different and incommensurable values.

Indeed, under the paradigm of individual autonomy, the value of autonomous rational agency is the only possible value, and therefore, its commensurability with any other value is logically ruled out. If the values of rational autonomous agency and satisfaction of subjective interests were commensurable with each other or with a higher order value, a coalescing network encompassing the networks corresponding to rights ${ }_{1}$ and rights ${ }_{2}$ might emerge. However, given that the underlying values are rival and incommensurable, the two networks cannot be consistently reshuffled, except by the expedient of maintaining common rule (2) and deleting all of the others. This drastic method would render the concept of rights superfluous once we introduce the concept of duties. Because no useful reshuffling of the semantic networks is possible, conceptual fragmentation generates radical meaning variance under conditions of value incommensurability.

The thesis of the radical variation of the meaning of rights can be also expressed by appealing to the parallelism with theoretical terms. Just as theoretical terms deployed in theory $(T)$ may be impossible to translate into the terminology of a theory $\left(T^{\prime}\right)$, the term rights embodied in value paradigm $V_{1}$ cannot be translated into the normative vocabulary of value paradigm $V_{2}$ because the semantic networks defining the meaning of each term cannot be coalesced back into an overlapping network due to the rivalry and incommensurability of the underlying values.

What is the relation between diachronic value pluralism and the semantic fragmentation of normative terms? Let us say that a normative term $(t)$ is embedded in value paradigm $(V)$ when some statements containing $t$ are true in all possible worlds in which the values embodied in $V$ exist but are false in some possible worlds in which the values embodied in $V$ do not exist. For instance, the term right is embedded in the paradigm of individual autonomy because the statement that "people have a right to privacy" is true in all possible worlds in which individual autonomy is valuable but false in some possible worlds in which individual autonomy is not a value, for example, a world $(W)$ in which privacy does not contribute to any value existing in $W$. Now if values deployed in $V_{1}$ and $V_{2}$ are rival and incommensurable, the meaning of $t$ in $V_{2}$ may be radically different from the meaning of $T$ in $V_{1}$. Both paradigms may have inconsistent normative consequences because they embody conflicting values. This inconsistency is likely to be reflected in 
the meaning of $t$. And given that those values are incommensurable with each other, the normative inconsistency cannot be reconciled by a procedure that ranks or weighs those values. Rivalry and incommensurability of value paradigms generate the radical semantic fragmentation of the normative terms embedded in those paradigms. The term radical means here that a coalescing back of the fragmented meanings is not possible. To put it briefly, value-laden normative terms are radically different in meaning if the values with which they are laden are both rival and incommensurable to one another.

Because the thesis about the radical semantic variance of value-laden normative terms bears resemblance to the thesis of the radical meaning variation of theory-laden scientific terms, it is useful to note that there are three main differences between the semantic variation of scientific terms and that of normative terms such as right.

First, although theoretical terms cannot be defined in a theoretically neutral language because they are theory-laden, some normative terms cannot be defined in a value-neutral language because they are valueladen, and the values with which they are laden are, in turn, incommensurable with each other. This means that although meaning variance of theoretical terms explains the incommensurability of scientific theories, meaning variance of normative terms depends on value incommensurability. The notion of dependence relevant here is a negative one. If the value paradigms in which normative terms are embedded were commensurable with one another, the fragmented semantic networks could coalesce back into a consistent network, and radical meaning variance would not exist. However, this process is not possible because rival and incommensurable value paradigms have irreconcilably inconsistent normative consequences.

Second, although there is widespread consensus that scientific terms have a fundamental referential or extensional dimension, many metaethical positions assign, if at all, only a limited importance to the referential function of normative terms. ${ }^{53}$ Empirical terms in scientific

53. Metaethics is the philosophical study of moral language and thinking; it is typically conducted in a second order language or metalanguage. Noncognitivist metaethical theories emphasize the expressive function of moral utterances, instead of their denotation or reference-also called extension. See SIMON BLACKBURN, EsSAYS IN Quasi-Realism 54 (1993); Simon Blackburn, Ruling PASSIONS 49-50 (1998); STEPHEN DARWALL, THE BRITISH MORALISTS AND THE INTERNAL 'OUGHT': 1640-1740, at 9-10 (1995); Allan GibBard, Wise ChOices, Apt FeElings 7-8 (1990); R.M. HaRe, FrEedOM AND REASON 189-91 (1963); R.M. HARE, Moral THINKING 207-08 (1981); 
theories refer to the natural world, and therefore, co-reference of empirical terms used by older and newer theories may allow theory comparability. Meaning invariance secured by co-reference may be all we need to compare two theories and choose one as closer to the truth. However, this does not apply to theoretical terms, such as mass, that lack direct reference to empirical phenomena. In the absence of co-reference, the meaning of theoretical terms is established by clusters of interrelated terms. Theoretical terms can be likened to normative terms because none of them can be solely defined in an extensional way. Because no referential analysis can exhaust the meaning of a normative term such as rights, the semantic variation of this term implies that both "rightsdiscourses" are untranslatable to each other. Therefore, showing that meaning variance is compatible with invariance of reference is of no consequence for the discussion of the semantic incommensurability of rights.

Finally, unlike successive scientific theories that entirely replace older ones, value paradigms typically evolve by accretion, which means that at any given time we do not encounter pure paradigms but rather mixed value paradigms that maintain older ones - though often within more restricted scopes. Thus, in contemporary legal cultures, the individual autonomy paradigm and the paradigm of collective interests coexist in Berlinian fashion, giving rise to tensions and conflicts that cannot be solved by reference to one neutral, all-encompassing value. Older individualist values still are there because even though most of us are not farmers and ranchers in modern industrial democracies, we stick to the view of ourselves as autonomous beings, though perhaps uncomfortably so within crowded cities and factories.

Although the Will Theory fragmentarily captures the classical features of rights, especially those associated with rights in deontological moral thinking, the Interest Theory seeks to accommodate the widely different kinds of rights that modern legal systems recognize and their various justifications in subjective interests. Given the rivalry and incommensurability of the values underlying both theories and the semantic variation of rights embedded in each theory, it is impossible to provide a rational single unified analysis of rights that does justice to the diverse and changing values that have shaped its various meanings.

R.M. Hare, The Language of Morals 180 (1952); Horacio Spector, Analytische UND POSTANALYTISCHE ETHIK (1993); CHARLES L. STEVENSON, ETHICS AND LANGUAGE 34-35 (1944). 


\section{THE Minimal MEANING OF RIGHTS}

The meaning of moral terms does not remain invariant across distinct value paradigms, even if the same names are maintained. Now, because new value paradigms often retain the old normative vocabulary, the problem of the semantic variation of normative terms is seldom addressed, even by theorists who endorse value incommensurability. ${ }^{54}$ Radicals who adopt a revisionist stance and try to eliminate some old normative terms can always be encountered. For example, Jeremy Bentham, a well-known defender of the paradigm of collective interests, rejected natural rights with the famous dictum: "Natural rights are nonsense upon stilts." 55 But the language of rights has survived this radical assault and has been transferred from the classical paradigm to the new paradigm.

The paradigm of subjective interests did not replace the old term, but radical conceptual change did occur, despite the fact that rights ${ }_{1}$ and rights $_{2}$ share rule (2), that is, that correlativity to duties is a common feature of both concepts of rights. This fact alone could not explain why the term rights is maintained as distinct from duties. Although rights ${ }_{1}$ and rights ${ }_{2}$ have radically different meanings because they are embedded in conflicting and incommensurable value paradigms, both terms share a minimal meaning. This semantic core can be couched in the following inferential rule:

(4) Acceptance of " $A$ has a right against $B$ that $B$ does not do $X$ " commits one to accepting that "state coercion can permissibly be used, or must be used, to secure fulfillment of B's duty to A not to do $X$."

Curiously, neither the Will Theory nor the Interest Theory emphasizes the minimal meaning conveyed by inferential rule (4). Yet Kant was mindful of this feature of rights. In locating rights in the Doctrine of Right, he implicitly assumed that the point of moral rights, as opposed to moral duties, is to establish the conditions for the use of permissible

54. For instance, Joseph Raz offers a unified analysis of rights in RAz, supra note 26, at 165-66. The great exception is Alasdair MacIntyre. See supra note 15 and accompanying text.

55. Jeremy Bentham, Anarchical Fallacies, in 'NONSENSE UPON STILTS': BENTHAM, BuRKE, AND MARX ON THE RigHTS OF MAN 46, 53 (Jeremy Waldron ed., 1987). 
coercion in society. ${ }^{56}$ In this respect, as in many others, Hart follows Kant. Hart also claims that rights justify the use of public force. ${ }^{57}$

The semantic variation of the term right must be accordingly qualified. Although the term cannot be defined across incommensurable value paradigms, it has a common core that seems to be paradigm invariant. Right is conceptually tied to state or public enforceability. This is a minimal content, though. A theorist of rights would probably not be content with just claiming that rights are "events of any kind that may or must be secured by state coercion." But it was perhaps this minimal content of rights that made the term's maintenance useful. The important point is that the thesis of semantic variation does not stand in the way of the minimalist view, that is, the view that rights has an invariant core meaning across various normative vocabularies associated with incommensurable value paradigms. This meaning is reflected in the basic fact that rights discourse performs a political function, whichever values that discourse seeks to respect or promote. Although this view falls short of revealing the value assumptions that have shaped the semantics of rights, the paradox is that any analysis of rights that goes beyond the minimalist view will ultimately flounder in the waters of diachronic value pluralism and its resultant fragmentation of meaning.

56. KANT, supra note 45, at 31-32.

57. H.L.A. Hart, Are There Any Natural Rights?, 64 PHIL. REV. 175, 175-91 (1955). 